\title{
The impact of microgeometry pistons with a stepped bearing surface for the friction loss of the internal combustion engine
}

\author{
Emil Wroblewski ${ }^{1, *}$, Antoni Iskra $^{1}$, and Maciej Babiak ${ }^{1}$ \\ ${ }^{1}$ Poznan University of Technology, Faculty of Machines and Transport, ul. Piotrowo 3, 60-965 Poznan, Poland
}

\begin{abstract}
This paper present the results of experimental piston friction losses on stepped bearing surface microgeometry obtained on the test rig. This test rig is equipped with special temperature control system, which provides better stability to temperature than in standard systems. The results of station tests was discussed. Tests was analyzed depending the moment caused by the friction on the oil temperature in the oil sump. Specified conclusions allow to assess the impact of the stepped profile of the pistons bearing surface microgeometry for different values of engine speed and the oil temperature at the friction losses in the main kinematic engine node which is piston-cylinder.
\end{abstract}

\section{Introduction}

The bearing surface of the piston, especially on the pressure side, is subjected during operation of internal combustion engine to significant mechanical loads. This situation is associated with the continuous improvement of internal combustion engines and therefore with increasing values of basic indicators of operating an internal combustion engine, such as power and maximum torque [1-2]. To assess technical condition and working conditions of combustion engine, parameters and characteristics of vibration signal generated by combustion engine are more and more often used [3-4]. The growth of these indicators is a direct result of the maximum pressure level increase inside the cylinder during the power stroke and also effective pressure. This fact has its direct impact on the size of the forces acting on the elements of the crank mechanism of piston as well as the strength of the normal forces at the bearing surfaces of the piston [5]. In addition, increasing the mean effective pressure can increase local temperatures in cooperating elements of the piston-crank mechanism, especially those in direct contact with the high temperature exhaust gas, e.g. the bottom of the piston [6-8]. This hard environment where parts of the piston-crank mechanism works, especially the piston, causes the certain problems in providing desired stability and reliability of the pistoncrank mechanism and minimizing fuel consumption at the same time [9].

One method of improving the durability of the cylinder liner and the bearing surface of the piston and reduced fuel consumption as well, is the use of appropriate coatings on the side surfaces of the pistons. The coatings are applied to the support surface of almost all modern pistons natural aspirated and supercharged engines $[6,10-11]$. Purpose of usage of them is primarily to avoid seizing of the piston in adverse operating conditions as [1]:

- local reduce of the piston slack caused by the deformation resulting from thermal and mechanical cylinder loads,

- reduce the slack of the piston as a result of overheating,

- insufficient oil film thickness at the time of starting the engine,

- worse properties of the oil caused by the heat,

- the state of the engine before the run-in.

The test results clearly confirm the positive role of the standard coating in reduce the possibility of scuffing the piston in the cylinder and reduce the surface wear of the cylinder under the normal engine operating conditions. In real operating conditions the total friction losses depend primarily on the liquid friction conditions so the use of coating does not give direct large benefits in reducing friction $[6,12]$.

Modification of the bearing surface shape on the piston consists of choosing the shape of the surface which is making the reciprocating motion regard to the cylinder liner to ensure the continuity of the oil film with the smallest possible value of the friction losses at the node between piston and cylinder. Reducing friction losses will contribute to the achievement of greater mechanical efficiency of the internal combustion engine and thus reduce fuel consumption [13-14].

Step-shaped gap can be obtained by the application of the $\mathrm{H}$ shaped graphite layers on the supporting surface of the piston. This will give the stepped profile which is characterized by a favorable tribological properties of the cylinder-piston kinematic couple fluid friction conditions, and use of graphite can expected advantageous properties in terms of boundary friction [15-16].

The article presents the results from research model of cooperation between experimental pistons with

Corresponding author: emil.z.wroblewski@doctorate.put.poznan.pl 
stepped microgeometry bearing surface and the cylinder wall at simulation bench for measuring friction losses in the conditions of the engine test bench.

\section{Developing support surface}

Adopted ennobling layer shape on the supporting surface is a continuation of earlier studies [14-17]. Friction losses can be reduced by such shaping of the gap between the piston and the cylinder (figure 1), which will provide continuous generation of the oil film separating the mating surfaces. Oil film reduces friction losses but not eliminate them. This is due to the energy balance. Viscous forces perform a work which immediately is converted into heat, manifested by an increase in temperature of oil layer which form film.

Method for obtaining reduction of friction losses in the piston-cylinder node is the use of a stepped microgeometry profile of the piston bearing surface by applying on a supporting surface of the piston graphite layers $\mathrm{H}$-shaped. Optimize $\mathrm{H}$ bar shall be verified experimentally by the method of determining the friction loss in the oil film produced as a result of hydrodynamic phenomena in the layer of oil between the bearing surface of the piston and cylinder.

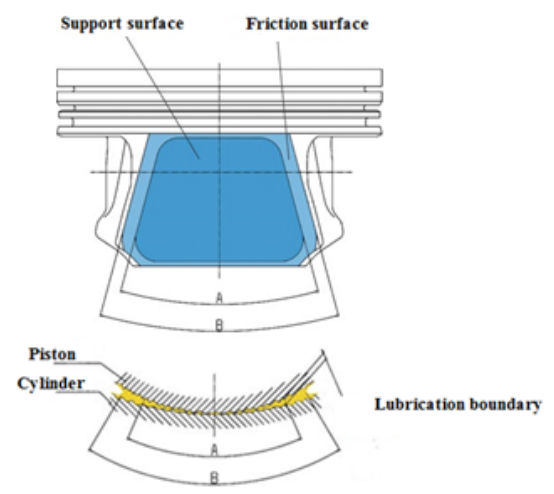

Fig. 1. Contact of the piston with the cylinder wall [6].

There were analyzed three experimental variants of the pistons with different bar position of an H-shape up or down relative to the symmetrical position. Figure 2-4 is shown in the drawings embodiments developed profiles of experimental pistons. Different variants of the pistons are presented in Fig. 5.

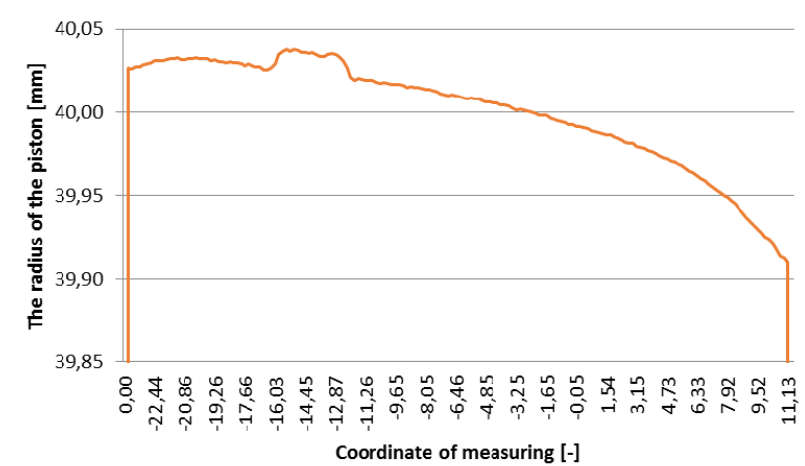

Fig. 2. Profile of the piston TR4.

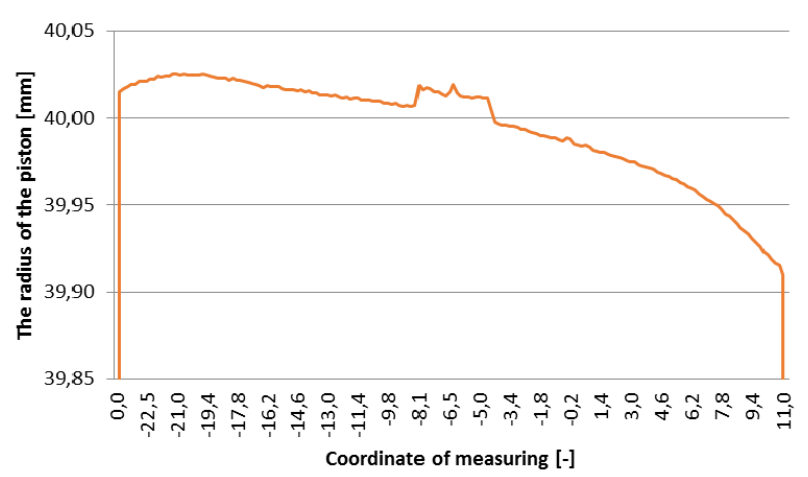

Fig. 3. Profile of the piston TR5.

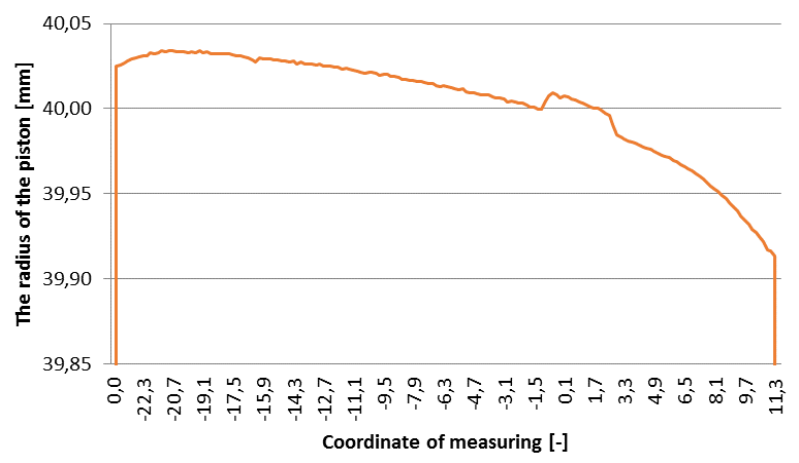

Fig. 4. Profile of the piston TR6.

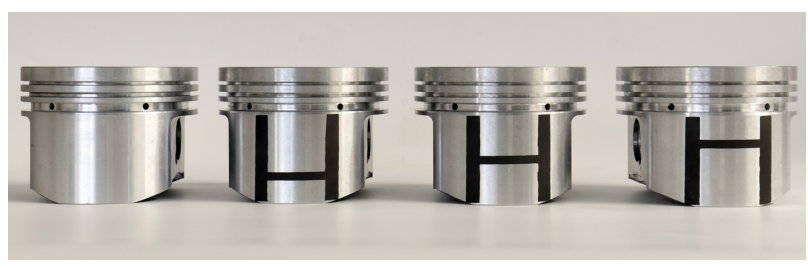

Fig. 5. View of different piston variants - Reference, TR4, TR5, TR6.

\section{Research position}

The test bench (Fig. 6) was built with a complete engine block FIAT 170A.046 with the crankshaft, connecting rods, pistons and cylinder head, in order to reproduce as closely as possible the actual working conditions of piston-engine crankshaft in the engine, while ensuring accurate measurement of torque under external drive.

There were built model for test bench to measure friction loss in the piston-cylinder group composed of the modified internal combustion engine driven electric motor from outside. Drive is transmitted through the shaft of the measuring shaft that allow accurate torque measurement with high temporal resolution. In addition, the engine camshaft has been immobilized, leaving all valves in the closed position, the immobilized crankshaft-driven coolant pump and an oil pump outer replacing them, driven by electric motors.

The changes made during each revolution of the crankshaft forces the repeating cycle of compression and expansion of the load confined within the cylinder, wherein the portion of the load due to leakage enters the crankcase. With the valves closed engine loss charge in 
the cylinder can be supplemented by additional nonreturn valves mounted instead of spark plugs. The design position allows you to close the valves or their opening to allow free air intake, ambient or bringing it under certain hypertension. Bringing the cylinder at the beginning of the stroke compressed air under increased pressure causes the increase in the maximum cylinder pressure. This is the method to simulate the actual increased engine load.

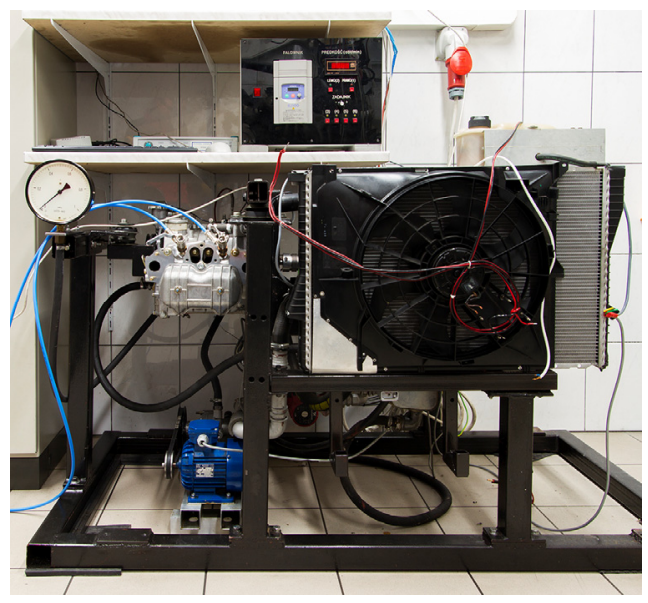

Fig. 6. The view of engine friction losses test bench.

A very important element of the original system to maintain a constant oil temperature of the heat exchanger oil-cooling liquid engine, the radiator and heater fluid and electrically powered pumps, coolant and oil. The PID controller makes it possible to maintain the desired oil temperature within $\pm 0.2{ }^{\circ} \mathrm{C}$, which ensures repeatability of the measurements. Diagram of stabilizing the oil temperature at the position shown in Fig. 8, and the most important technical data positions in Tab. 1. The torque meter combining combustion engines with an electric motor shown in Fig. 7. A detailed description of the position of the model is in the literature [18-19].

Table 1. Specifications of test bench simulation.

\begin{tabular}{|c|c|}
\hline Technical data & Description \\
\hline $\begin{array}{l}\text { Combustion } \\
\text { engine }\end{array}$ & $\begin{array}{l}\text { two-cylinder, liquid-cooled, } \\
\text { FIAT } 170 . \text { A046 }\end{array}$ \\
\hline Electric engine & Maximum continuous power $2,2 \mathrm{~kW}$ \\
\hline Rotation speed & $\begin{array}{l}\text { fluently controlled in the range } \\
\text { of } 500-3000 \mathrm{rpm}\end{array}$ \\
\hline $\begin{array}{l}\text { Torque } \\
\text { measurement }\end{array}$ & In scope $-50 \ldots .50 \mathrm{Nm}$, frequency $9,6 \mathrm{kHz}$ \\
\hline $\begin{array}{l}\text { Registration } \\
\text { results }\end{array}$ & $\begin{array}{l}\text { production unit HBM Spider } 8 \text { type, with } \\
\text { integrated power bridge strain gauge } \\
\text { measuring shaft }\end{array}$ \\
\hline Lubricating oil & Castrol Edge 5W30 \\
\hline $\begin{array}{l}\text { Oil } \\
\text { temperature }\end{array}$ & $\begin{array}{l}\text { Regulated in the range of } 40-110{ }^{\circ} \mathrm{C} \\
\text { the maximum error adjustment of } 0,2^{\circ} \mathrm{C}\end{array}$ \\
\hline Oil pressure & adjustable, equal to $0,4 \mathrm{MPa}$ \\
\hline Oil pump & $\begin{array}{l}\text { Wing type product of ZF, driven by an } \\
\text { electric motor with a power of } 0,4 \mathrm{~kW}\end{array}$ \\
\hline Coolant pump & $\begin{array}{l}\text { Grundfos production, } \\
\text { the liquid stream equal } 5 \mathrm{~m}^{3} / \mathrm{h}\end{array}$ \\
\hline Fluid heater & $\begin{array}{c}\text { Electric, with power adjustable in steps } \\
0,1,2 \text { and } 4 \mathrm{~kW}\end{array}$ \\
\hline
\end{tabular}

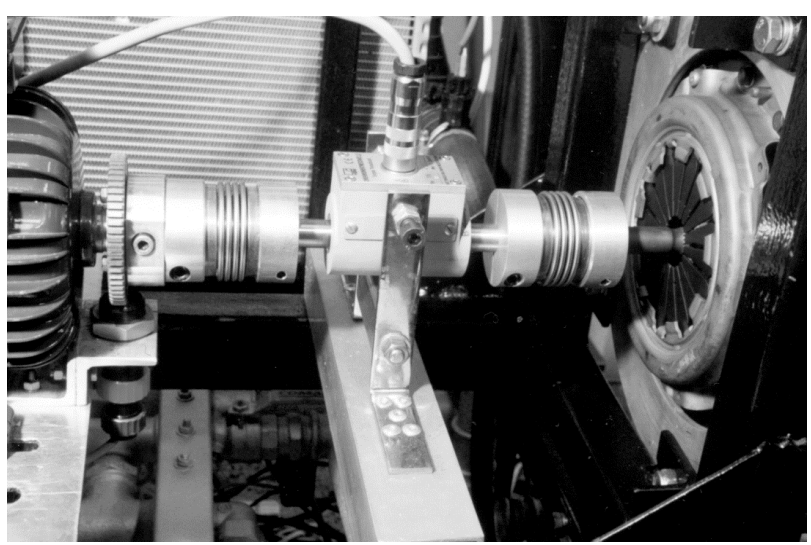

Fig. 7. Placement of a torque meter combining combustion engines with an electric motor [18].

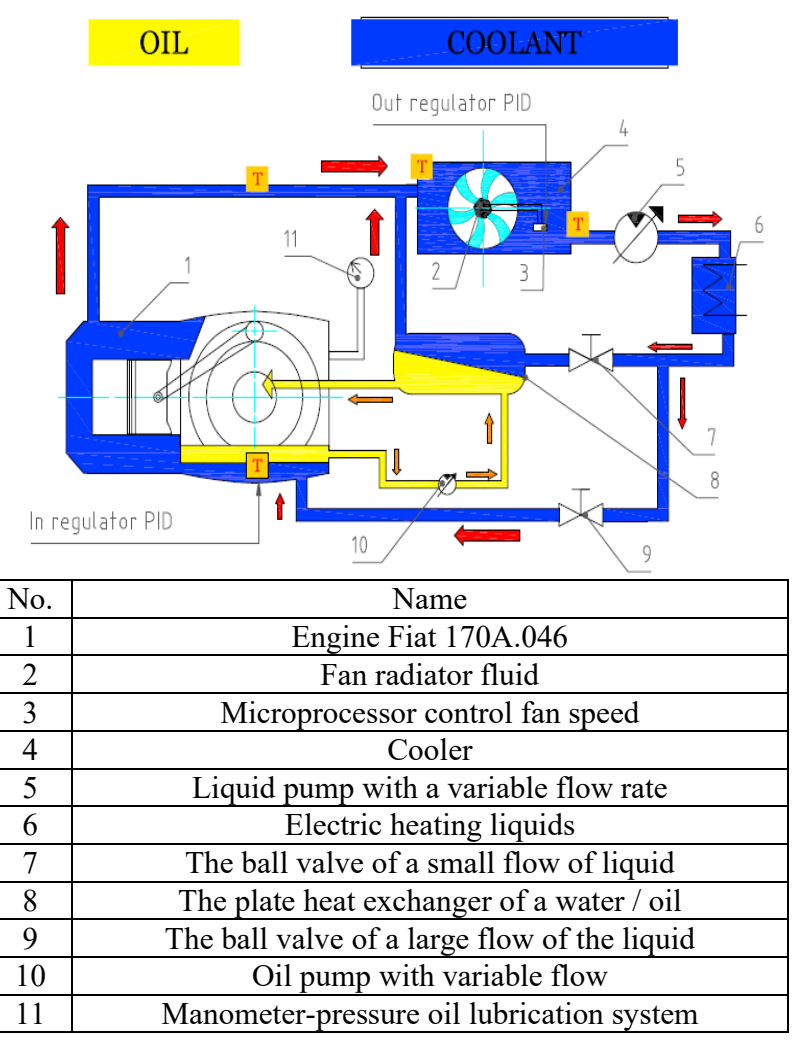

Fig. 8. Diagram of the oil temperature regulation system used on test bench.

\section{Research results}

The approach used in construction of test bench give opportunity to measure the torque with high accuracy and measurement frequency. The measured value of the torque due to the friction loss in the piston-crank mechanism is not significantly affected by the action of any other engine mechanism. Torque measurement is affected by the influence of thermodynamic phenomena that occur in the engine and blow-by charge to the crankcase.

The impact of these phenomena cannot be eliminated, but it can be assumed that their progress depends largely on microgeometry or covering coats of piston bearing surface and that allows each other 
comparison of these variants in the range of generated friction losses.

Measurements of friction losses made for the options of presented experimental microgeometry bearing surface of the experimental stepped piston profile and a surface of the barrel profile pistons serial used in the engine Fiat 170A.046. The measurements were carried out for the following conditions:

- $\quad$ speed 750-3000 rpm,

- oil temperature $50,80,110^{\circ} \mathrm{C}$,

- no supplement charge.

For each temperature of the oil was carried out five series of measurements - no refill load, which gave a lower pressure and a force of the compression gas. The results obtained are shown in Fig. 9-11.

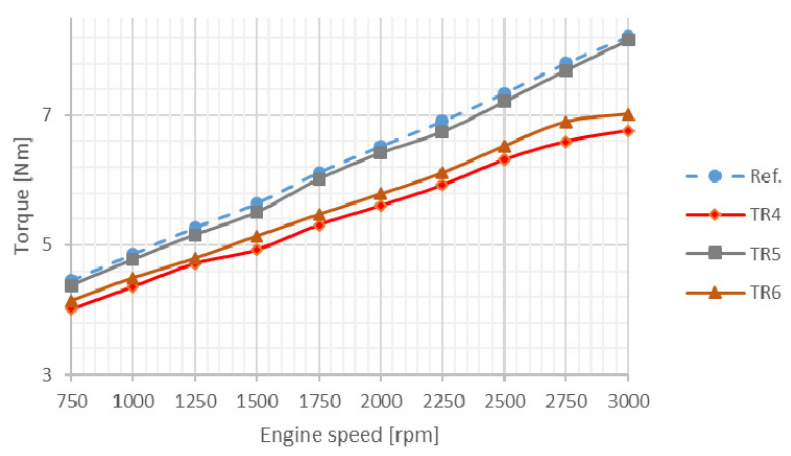

Fig. 9. The results of the measurements for oil temperature $50{ }^{\circ} \mathrm{C}$.

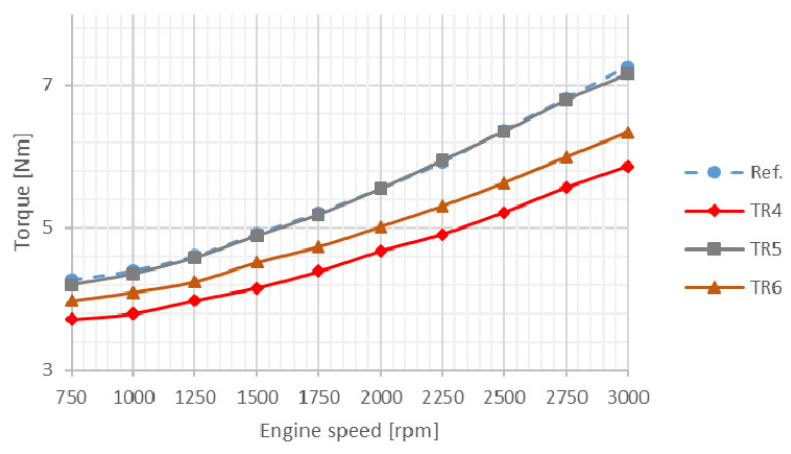

Fig. 10. The results of the measurements for oil temperature $80^{\circ} \mathrm{C}$.

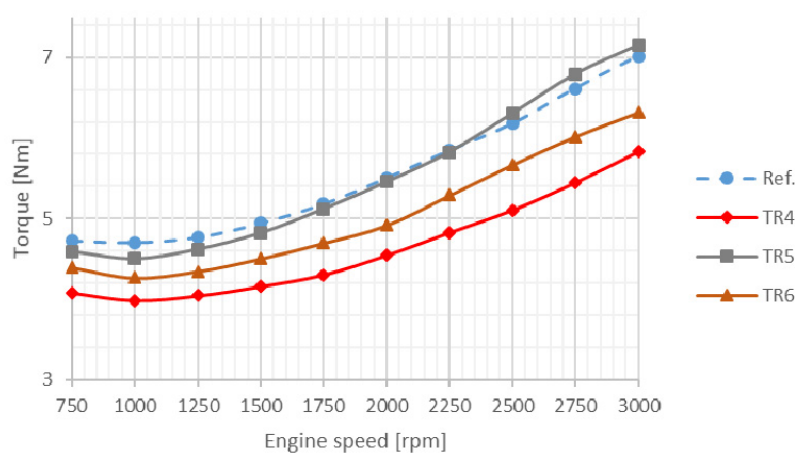

Fig. 11. The results of the measurements for oil temperature $110^{\circ} \mathrm{C}$.
Fig. 12-15 summarizes the results of the percentage reduction in friction losses in all options experimental pistons as a function of rotation speed.

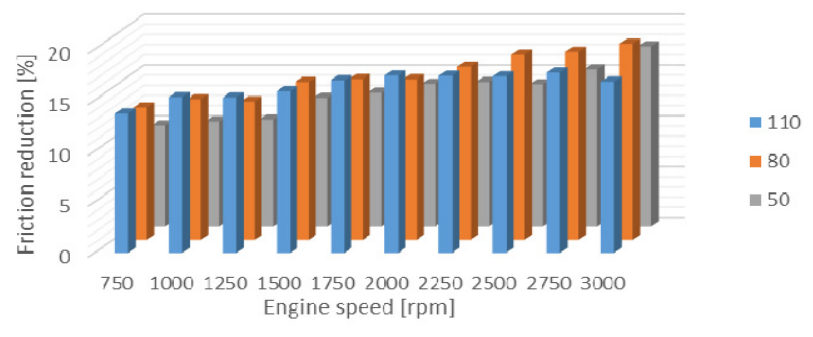

Fig. 12. Reduction of friction losses as a function of temperature and speed variant TR4.

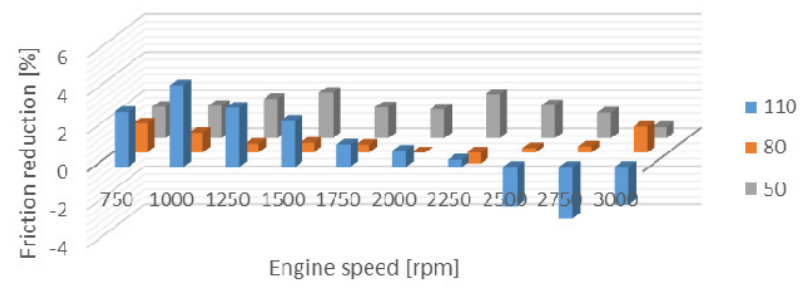

Fig. 13. Reduction of friction losses as a function of temperature and speed variant TR5.

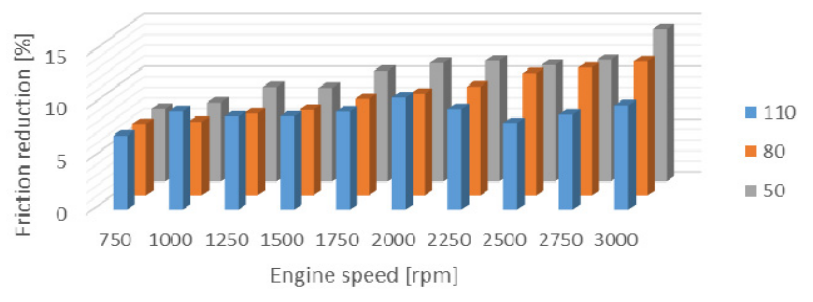

Fig. 14. Reduction of friction losses as a function of temperature and speed variant TR6.

Based on these results it can be seen that all the experimental variants of the piston with a stepped bearing surface microgeometry generate the desired reduction of friction in the piston-cylinder group, relative to the serial pistons. As it was expected from the hydrodynamic lubrication theory, increasing the rotational speed increases the braking torque.

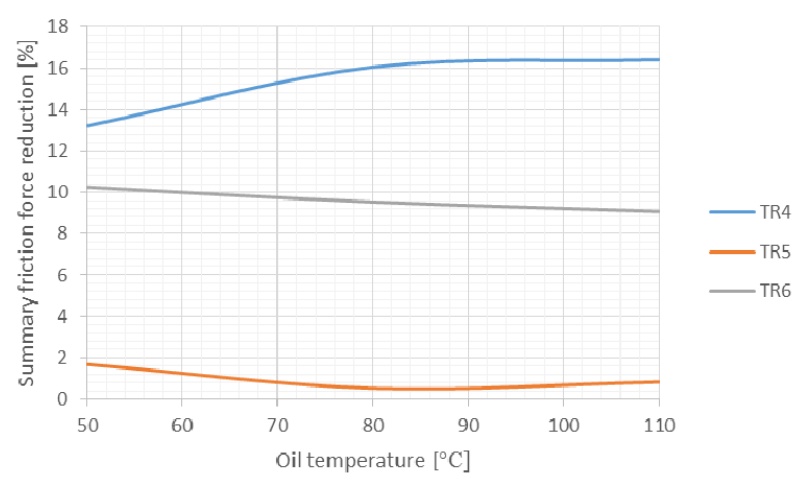

Fig. 15. The total reduction of the friction losses as a function of oil temperature. 
The result of measurement, showed the greatest reduction in friction variant TR4 (approx. 15\%), TR6 (approx. 10\%) and the lowest TR5 (approx. 1\%). On the basis of the results it can be also seen that a reduction in friction losses is greater for higher speeds of the engine crankshaft. This is an important observation, because while increasing the engine speed as a result of higher friction losses being converted into heat, it occurs faster heating in cooperating parts of the engine and in the lubricating oil. This leads to conditions of boundary friction. This phenomenon may, however, have a positive effect on the reduction of friction losses in the piston-cylinder group on the assumption that no boundary friction will occur at the interface between the bearing surface of the piston and the cylinder liner.

\section{Conclusions}

The study used the bench test, in which was measured precisely the total friction loss in the piston-crank mechanism and the other motor mechanisms are fixed or fitted with independent electric drive. Studies in experimental bench model of the motor pistons with a stepped profile bearing surface to estimate the value of the friction losses in the piston-crank mechanism and to draw the following conclusions:

- the use of microgeometry of the bearing surface stepped profile relative to the barrel allows for the reduction of friction losses thus increasing the mechanical efficiency of the engine and reducing fuel consumption,

- the application of the H-shape bearing surface of the piston allows to reduce friction loss average about $10 \%$ in relation to the barrel-like shape,

- it was showed the greatest reductions variant of the piston with the bar letter $\mathrm{H}$ shifted downwards relative to the position symmetric about $16 \%$, because this variant extended the area, it ensures the generation of a continuous oil film separating the cooperating surfaces,

- the coolant temperature regulates temperature of engine and oil, which affects the friction losses,

- for all oil temperatures along with the increase in rotational speed, experimental pistons showed a marked reduction in friction in relation to the barrellike shape. This is caused by a higher relative velocity of the moving elements of the engine and as a result of the higher temperature,

- increase speed at relatively constant temperature of the oil increases the loss of mechanical resistance,

- a stepped surface can be achieved by the coating of the support surface of the piston using lubricants like i.e. graphite,

- a layer of lubricants are particularly desirable under lack of continuity of oil film conditions.

The study presented in this article was performed within the statutory research (contract No. 05/52/DSPB/0262).

\section{References}

1. M. Blümm, A. Baberg, F. Dörnenburg, MTZ 2 (2016)

2. G.M. Szymanski, F. Tomaszewski, Proceedings of The 17th International Congress on Sound and Vibration (Cairo, 2010)

3. M. Orczyk, F. Tomaszewski, B. Czechyra, G.M. Szymanski, Proceedings of the International Congress on Sound and Vibration (Athens, 2016)

4. G.M. Szymanski, M. Josko, F. Tomaszewski, R. Filipiak, Mechanical Systems and Signal Processing 58-59, 298-307 (2015), 10.1016/j.ymssp.2014.12.017

5. A. Baberg, M. Freidhager, H. Mergel, K. Schmidt, MTZ 12 (2012)

6. M. Fahr, W. Hanke, C. Klimesch, A. Rehl, MTZ 7-8 (2011)

7. J. Merkisz, P. Fuc, P. Lijewski, A. Ziolkowski, K.T. Wojciechowski, Journal of Electronic Materials 44, 1704-1715 (2015), DOI: 10.1007/s11664-014-3522-6

8. J. Merkisz, P. Fuc, P. Lijewski, A. Ziolkowski, M. Galant, M. Siedlecki, Journal of Electronic Materials 45, 4028-4037 (2016), DOI: 10.1007/s1 1664-016-4543-0

9. G. Koszalka, Eksploatacja i Niezawodnosc Maintenance and Reliability 3, 40-44 (2011)

10. T. Deuss, H. Ehnis, R. Rose, R. Künzel, MTZ 5 (2010)

11. J. Merkisz, J. Mizera, M. Bajerlein, L. Rymaniak, P. Maj, Experimental and Applied Mechanics 518, 102-107 (2014), DOI: 10.4028/www.scientific.net/AMM.518.102

12. T. Deuss, H. Ehnis, R. Rose, R. Künzel, MTZ 4 (2011)

13. A. Iskra, P. Krzymień, E. Wróblewski, Combustion Engines 162, 192-196 (2015)

14. A. Iskra, M. Babiak, E. Wróblewski, Technika Transportu Szynowego 12, 644-647 (2015)

15. E. Wróblewski, A. Iskra, M. Babiak, Journal of KONES Powertrain and Transport 23, 431-436 (2016)

16. A. Iskra, M. Babiak, W. Wroblewski, IOP Conference Series-Materials Science and Engineering 148, UNSP 012068 (2016), DOI: 10.1088/1757-899X/148/1/012068

17. A. Iskra, E. Wróblewski, M. Babiak, Journal of Kones Powertrain and Transport 22, 95-101 (2015)

18. J. Kaluzny, Wpływ kształtu powierzchni nośnej tłoka na parametry filmu olejowego pokrywajacego gładź cylindra (Poznan, 2004)

19. E. Wróblewski, A. Iskra, M. Babiak, Journal of Mechanical and Transport Engineering 68, 2 (2016) 